\title{
Cerebral Nocardiosis in a Patient With Rheumatoid Arthritis Under Treatment With Tocilizumab
}

\author{
Juliana Lopes ${ }^{\mathrm{a}, \mathrm{d}}$, Sara Martins ${ }^{\mathrm{a}}$, Mariana Brandao ${ }^{\mathrm{a}, \mathrm{b}}$, Graziela Carvalheiras ${ }^{\mathrm{b}, \mathrm{c}}$, \\ Teresa Mendonca ${ }^{a, b}$, Fatima Farinha, ${ }^{a}$ b
}

\begin{abstract}
The use of biological therapy has revolutionized the treatment of various autoimmune diseases. Tocilizumab (TCZ) is a recombinant humanized antiinterleukin-6 (IL-6) receptor monoclonal antibody approved for the treatment of patients with rheumatoid arthritis, as monotherapy or in combination with other disease-modifying antirheumatic drugs (DMARDs). Clinical and post-marketing surveillance studies of TCZ indicate that infections are the most frequent adverse events. Most of the serious infections described are bacterial and viral, with no uncommon pathogens. The authors report a case of a patient with destructive rheumatoid arthritis under TCZ that presented with neurological symptoms and a right cerebellar lesion with marked diffusion restriction suggestive of cerebellar abscess. The microbiologic studies from aspirative cerebral biopsy revealed $\mathrm{No}$ cardia farcinica. With adequate antibiotics, the patient evolved with resolution of all symptoms and brain abscess at 5 months of followup. According to published reports, this is the first case of nocardial infection in patients under TCZ. The case highlights the importance of being aware of risk infection in these patients and need of an early diagnosis allowing a prompt treatment.
\end{abstract}

Keywords: Nocardia infection; Brain abscess; Rheumatoid arthritis; IL-6 receptor; Tocilizumab

\section{Introduction}

The use of biological therapy has revolutionized the treatment of various autoimmune diseases. These inflammatory diseases are associated with disabling pain, functional limitation and consequent impact on the quality of patients' lives. Failure to treat them properly in a timely manner can lead to irrevers-

\footnotetext{
Manuscript submitted December 24, 2017, accepted January 15, 2018

anternal Medicine Department, Centro Hospitalar do Porto, Porto, Portugal ${ }^{\mathrm{b}}$ Clinic Immunology Unit, Centro Hospitalar do Porto, Porto, Portugal 'Intensive Care Department, Centro Hospitalar do Porto, Porto, Portugal ${ }^{\mathrm{d} C}$ Corresponding Author: Juliana Lopes, Internal Medicine Department, Centro Hospitalar do Porto, Hospital de Santo Antonio, Porto, Portugal.

Email: mariajulopes@gmail.com
}

doi: https://doi.org/10.14740/jmc2995w ible damage and permanent disability $[1,2]$. Biologic therapy became a crucial part of the treatment approach. Each of them is catalogued according to its action target, and its benefit is reached at least partially to specific and targeted inhibition of key cytokines and cytokine pathways [3]. They include inhibitors of tumour necrosis factor (TNF), such as etanercept, infliximab, golimumab, certolizumab pegol, adalimumab, and non-TNF inhibitors including interleukin-1 (anakinra), interleukin-6 receptor (tocilizumab, TCZ ), CD80/86 (abatacept), and B lymphocyte (rituximab) [4].

Prior to the decision on the initiation of biological therapy, its harm must be weighed against its benefits for the patient with systemic disease. Fortunately, in general, TNF inhibitors are associated with low levels of infection associated with the use of adalimumab, etanercept and infliximab with an adjusted hazard ratio of $1.2(95 \% \mathrm{CI}: 1.1-1.5)$ [5].

TCZ is a recombinant humanized interleukin-6 (IL-6) receptor monoclonal antibody approved for the treatment of patients with rheumatoid arthritis, as monotherapy or in combination with disease-modifying anti-rheumatic drugs (DMARDs). Clinical and post-marketing surveillance studies of TCZ indicate that infections are the most frequent adverse events [6-8]. Most of the serious infections described are bacterial and viral, with no uncommon pathogens. Also, a longer disease duration, higher number of previous DMARDs and previous use of rituximab are identified as predictors of infection [9].

TCZ suppresses the production of proinflammatory acutephase reactants, including C-reactive protein (CRP), which raises a major concern that infections may be detected later and with presenting misleading clinical pictures [10].

The authors report a patient with cerebral nocardiosis under TCZ and methotrexate.

\section{Case Report}

We present a case of a 71-year-old female, living in an urban area, who had a previous 17 years evolving-history of destructive rheumatoid arthritis. Important involvement of small and large articulations led to progressive increase and adjustment of medication with methotrexate and high doses of corticosteroids. Because the disease was still active and disabling after full dose of conventional DMARDs, biological treatment with TCZ was instituted in 2011, finally achieving remission with subcutaneous TCZ, $162 \mathrm{mg}$ per week, associated with systemic corticotherapy, methotrexate and hydroxychloroquine. 


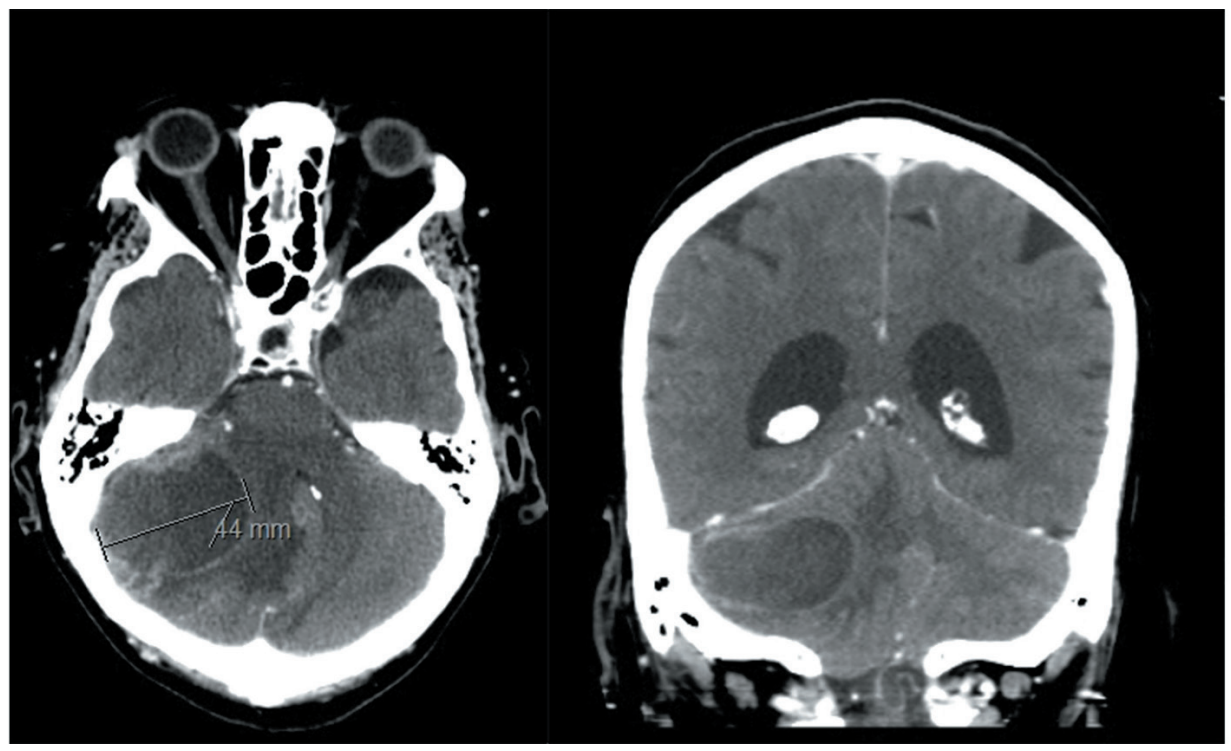

Figure 1. Head computed tomography (CT) showed a nodular cortico-subcortical intraparenchymal right cerebellar hemispheric lesion, with a 4-cm longer axis associated with vasogenic oedema, cerebellar parenchymal and brainstem deformation.

She presented in the emergency room after experiencing vomits, headache and dizziness for 4 days. Physical examination identified diplopy, horizontal nystagmus, right conjugated eye palsy, right dysmetria and occipital pain with anterior neck flexion. Computed tomography (CT) showed a nodular cortico-subcortical intraparenchymal right cerebellar hemispheric lesion, with a 4-cm longer axis, and irregular contrast captation in a ring enhancing pattern, associated with vasogenic edema, cerebellar parenchymal and brainstem deformation and right tonsillar descendence (Fig. 1). Magnetic resonance confirmed a single right cerebellar lesion with marked diffusion restriction and aspects suggestive of cerebellar abscess. Surgical image-guided drainage was performed, with recollection of purulent exudate allowing microbiologic isolation of Nocardia $s p$., specifically Nocardia farcinica identified with molecular technique (Fig. 2).

At this point, she was already under antibiotherapy with trimethoprim-sulfamethoxazole ( $15 \mathrm{mg} / \mathrm{kg}$ IV per day) plus imipenem (500 mg IV per day), and since the patient had no other symptoms indicative of a primary local of infection, a full body $\mathrm{CT}$ was performed. It revealed multiple lung nodules, the largest with $5 / 6 \mathrm{~mm}$ of diameter; interstitial upper right lobe thickening; and small volume bilateral pleural effusion. Bronchofibroscopy with broncho-alveolar lavage microbiologic studies was performed but no isolation was obtained, probably because antibiotic therapy was already initiated. Despite that, the complete resolution of pleural effusion and interstitial thickening in a revaluation CT was suggestive of

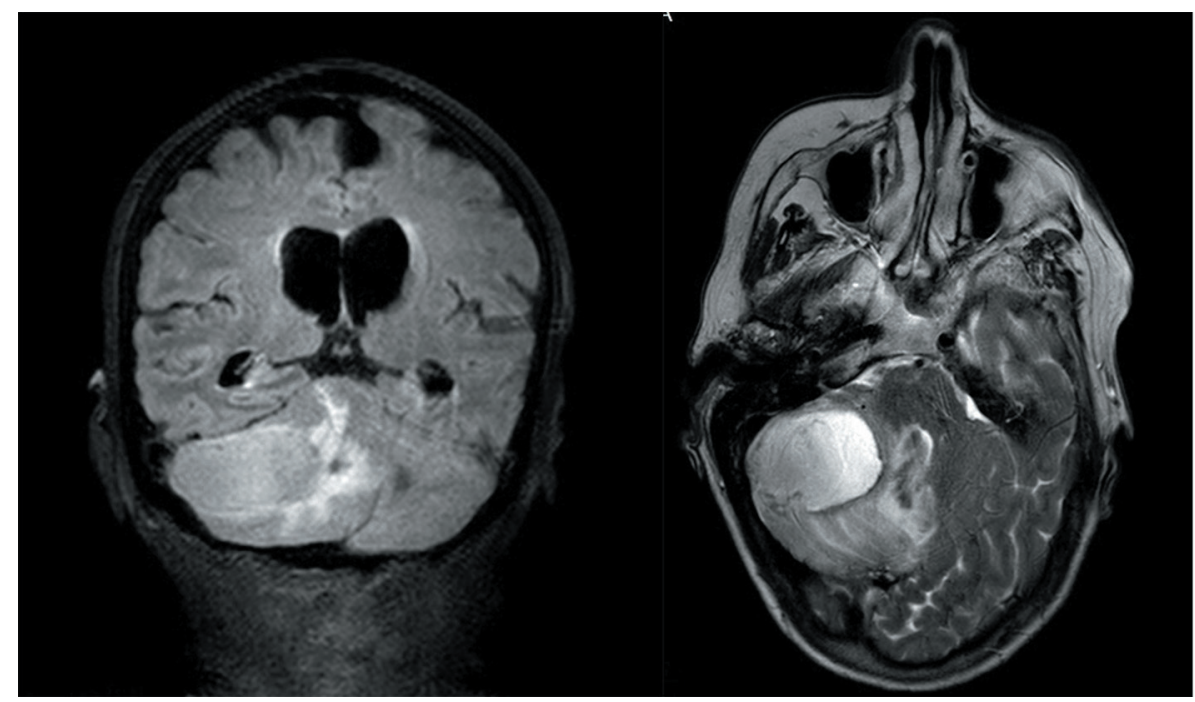

Figure 2. Head magnetic resonance showing single right cerebellar lesion with marked diffusion restriction and aspects suggestive of cerebellar abscess. 


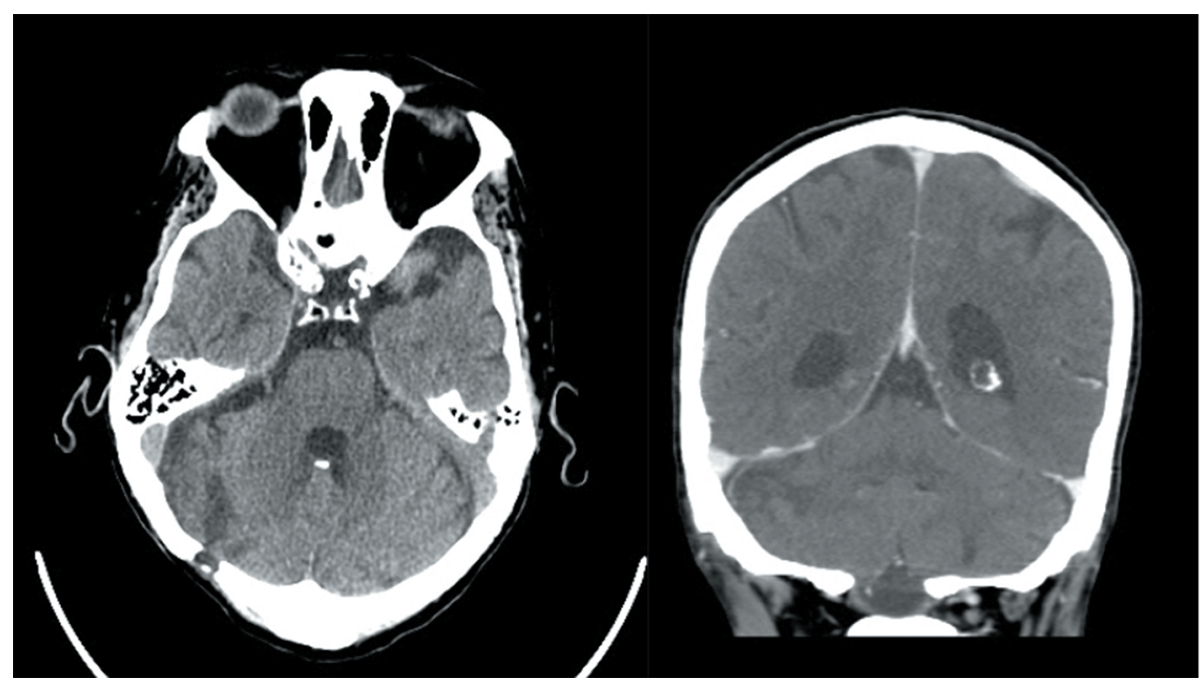

Figure 3. Head computed tomography (CT) 6 months with therapeutics revealing complete resolution of the cerebral abscess.

pulmonary nocardiosis, which is congruent with the fact that lung is the most common point of entry for nocardial infection.

The patient had a fast symptomatic relieve with surgical drainage and high dose systemic corticotherapy. Control imaging showed regression of the abscess and resolution of signs of edema and secondary mass effect, and the patient was discharge after 6 weeks of intravenous double antibiotherapy with imipenem and sulfamethoxazole/trimethoprim, and indication for maintaining oral sulfamethoxazole/trimethoprim to complete a full year treatment for invasive nocardial disease.

At the 5 months post-discharge evaluation, the patient was still under oral antibiotic treatment, remaining free from neurological symptoms and normal CT scan (Fig. 3), but with impaired functioning and quality of life secondary to arthritis reactivation. Corticoids and methotrexate were carefully reintroduced, under clinical and imagiologic tight surveillance, with partial response.

\section{Discussion}

Nocardia species are ubiquitous bacteria that usually manifest as an opportunistic infection in immunocompromised hosts. It can be found in soil, organic matter and fresh and salt water. There are more than 50 species identified and at least 30 species are pathogenic, leading to a challenging taxonomy. Nocardia asteroids is the more implicated in human infection and includes $N$. asteroides sensu stricto, $N$. farcinica, $N$. cyriacigeorgica, N. nova, and N. abscessus [11].

These bacteria are usually responsible for infection in immunocompromised patients, but one-third of nocardia infections are in immunocompetent patients. Patients with depressed cell-mediated immunity are at high risk for infection, including those suffering from human immunodeficiency virus infection, solid-organ or hematopoietic stem cell transplant and those receiving long-term treatment with steroids or other medications that suppress cell-mediated immunity [12].
In fact, cellular immunity is central in controlling nocardial infection and abscess formation. Also, nocardial infection is a continuous trigger neutrophil recruitment for abscess formation, preventing successful clearance of infection $[13,14]$.

The infection is acquired by inhalation or direct contact with the bacteria and consequent primary pulmonary or skin disease. Pulmonary nocardiosis is the most common presentation. It can occur hematogenous dissemination causing extrapulmonary nocardiosis. Disseminated nocardiosis is defined as two or more non-contiguous sites of involvement that may or may not include a pulmonary infection [15].

The central nervous system (CNS) is the most common extrapulmonary location for nocardiosis and it could appear in the form of meningitis or brain abscess. It can present with nausea, vomiting, seizures, or alteration in consciousness, gradually or with acute presentation, usually does not exhibit symptoms such as fever, and it can be accompanied by other system infections [16].

Nocardial abscesses can be single or multiple and normally are located at supratentorial lobe but virtually can occur in any region of the brain [17]. The definitive diagnosis of nocardial infection is obtained from specimen culture and microscopic examination. The bacteria normally grow on nonselective media routinely used but, in specimens containing mixed flora, nocardia colonies can be obscured by other rapidly growing bacteria [18].

Nocardia farcinica brain abscess has a high mortality rate, at least $50 \%$ in immunocompromised patients [19]. The risk of CNS infection is higher for $N$. farcinica than for other species (from $15 \%$ to $30 \%$ ) associated with high mortality rates. It seems to be more virulent and tends to disseminate more frequently [20]. So, it is vital to identify specific nocardia species because many strains are multidrug resistant to antibiotics. Hence, because of this sensitivity, appropriate specimen collection and treatment are vital [21]. In this case, an early diagnosis with prompt identification of nocardia species allowed an adequate antibiotherapy with a good result.

Nocardiosis is a complication in patients under biologic 
therapy. As reviewed, there are 10 cases described in literature, all under anti-TNF therapy [22-31]. To our knowledge, this is the first described case of nocardiosis in a patient under TCZ. The randomized controlled trials of TCZ described several infectious, bacterial and viral mostly and only a few associated to opportunist pathogens. So, it is not reported an increased infectious risk with TCZ compared with placebo and the rate of serious infectious is in the range observed with other biologics $[32,33]$. This case raises the concern about mechanism behind opportunist infection and how to reach an early diagnosis. With IL-6 suppression, it is expected a risk increase, once IL-6 and CRP pay an important role in acute phase response and action against different microorganisms. Consequently, infections are at risk of a late diagnosis because of the masking effect.

Despite the therapy with TCZ at the moment of infection, the reported patient had an actual and past of immunosuppressors that rise the cumulative risk of serious infection in association to a longer disease duration and previous use of rituximab which are identified as predictors of infection [9]. The actual contribution of TCZ to infection susceptibility is yet to know, as its use experience rises.

Most clinical trials reported the safety of TCZ; either way, this case report highlights the importance of a cautious therapy decision and close follow-up during all treatments.

\section{Conflict of Interest}

There is no conflict of interest.

\section{Funding}

No external funds were used for this research study.

\section{References}

1. Kvien TK, Uhlig T. Quality of life in rheumatoid arthritis. Scand J Rheumatol. 2005;34(5):333-341.

2. Yelin E. Work disability in rheumatic diseases. Curr Opin Rheumatol. 2007;19(2):91-96.

3. Bulpitt KJ. Biologic therapies in rheumatoid arthritis. Curr Rheumatol Rep. 1999;1(2):157-163.

4. McInnes IB, Schett G. The pathogenesis of rheumatoid arthritis. N Engl J Med. 2011;365(23):2205-2219.

5. Galloway JB, Hyrich KL, Mercer LK, Dixon WG, Fu B, Ustianowski AP, Watson KD, et al. Anti-TNF therapy is associated with an increased risk of serious infections in patients with rheumatoid arthritis especially in the first 6 months of treatment: updated results from the British Society for Rheumatology Biologics Register with special emphasis on risks in the elderly. Rheumatology (Oxford). 2011;50(1):124-131.

6. Nishimoto N, Miyasaka N, Yamamoto K, Kawai S, Takeuchi T, Azuma J. Long-term safety and efficacy of tocilizumab, an anti-IL-6 receptor monoclonal antibody, in monotherapy, in patients with rheumatoid arthritis (the STREAM study): evidence of safety and efficacy in a 5-year extension study. Ann Rheum Dis. 2009;68(10):1580-1584.

7. Genovese MC, Rubbert-Roth A, Smolen JS, Kremer J, Khraishi M, Gomez-Reino J, Sebba A, et al. Longterm safety and efficacy of tocilizumab in patients with rheumatoid arthritis: a cumulative analysis of up to 4.6 years of exposure. J Rheumatol. 2013;40(6):768-780.

8. Koike T, Harigai $M$, Inokuma $\mathrm{S}$, Ishiguro $\mathrm{N}$, Ryu J, Takeuchi T, Takei S, et al. Effectiveness and safety of tocilizumab: postmarketing surveillance of 7901 patients with rheumatoid arthritis in Japan. J Rheumatol. 2014;41(1):15-23.

9. Lang VR, Englbrecht M, Rech J, Nusslein H, Manger K, Schuch F, Tony HP, et al. Risk of infections in rheumatoid arthritis patients treated with tocilizumab. Rheumatology (Oxford). 2012;51(5):852-857.

10. Nishimoto N, Terao K, Mima T, Nakahara H, Takagi N, Kakehi T. Mechanisms and pathologic significances in increase in serum interleukin-6 (IL-6) and soluble IL-6 receptor after administration of an anti-IL-6 receptor antibody, tocilizumab, in patients with rheumatoid arthritis and Castleman disease. Blood. 2008;112(10):3959-3964.

11. Brown-Elliott BA, Brown JM, Conville PS, Wallace RJ, Jr. Clinical and laboratory features of the Nocardia spp. based on current molecular taxonomy. Clin Microbiol Rev. 2006;19(2):259-282.

12. Long PF. A retrospective study of Nocardia infections associated with the acquired immune deficiency syndrome (AIDS). Infection. 1994;22(5):362-364.

13. Montoya JP, Carpenter JL, Holmes GP, Hurley DL, Winn R. Disseminated Nocardia transvalensis infection with osteomyelitis and multiple brain abscesses. Scand J Infect Dis. 2003;35(3):189-196.

14. Filice GA. Inhibition of Nocardia asteroides by neutrophils. J Infect Dis. 1985;151(1):47-56.

15. Corti ME, Villafane-Fioti MF. Nocardiosis: a review. Int J Infect Dis. 2003;7(4):243-250.

16. Bross JE, Gordon G. Nocardial meningitis: case reports and review. Rev Infect Dis. 1991;13(1):160-165.

17. Lee GY, Daniel RT, Brophy BP, Reilly PL. Surgical treatment of nocardial brain abscesses. Neurosurgery. 2002;51(3):668-671; discussion 671-662.

18. Saubolle MA, Sussland D. Nocardiosis: review of clinical and laboratory experience. J Clin Microbiol. 2003;41(10):4497-4501.

19. Lerner PI. Nocardia species. In: Mandel GL, Douglas R, Bennet JE (eds). Principles and practice of infectious diseases. New York. Churchill Livingstone, 1995; p. 22732280.

20. Miralles GD. Disseminated Nocardia farcinica infection in an AIDS patient. Eur J Clin Microbiol Infect Dis. 1994;13(6):497-500.

21. Wauters G, Avesani V, Charlier J, Janssens M, Vaneechoutte M, Delmee M. Distribution of nocardia species in clinical samples and their routine rapid identification in the laboratory. J Clin Microbiol. 2005;43(6):2624-2628.

22. Singh SM, Rau NV, Cohen LB, Harris H. Cutaneous nocardiosis complicating management of Crohn's disease with 
infliximab and prednisone. CMAJ. 2004;171(9):10631064.

23. Ali T, Chakraburtty A, Mahmood S, Bronze MS. Risk of nocardial infections with anti-tumor necrosis factor therapy. Am J Med Sci. 2013;346(2):166-168.

24. Fabre S, Gibert C, Lechiche C, Jorgensen C, Sany J. Primary cutaneous Nocardia otitidiscaviarum infection in a patient with rheumatoid arthritis treated with infliximab. J Rheumatol. 2005;32(12):2432-2433.

25. Stratakos G, Kalomenidis I, Papas V, Malagari K, Kollintza A, Roussos C, Anagnostopoulou M, et al. Cough and fever in a female with Crohn's disease receiving infliximab. Eur Respir J. 2005;26(2):354-357.

26. Parra MI, Martinez MC, Remacha MA, Saez-Nieto JA, Garcia E, Yague G, Guardiola J. Pneumonia due to Nocardia cyriacigeorgica in a patient with Crohn's disease treated with infliximab. J Crohns Colitis. 2008;2(4):331332 .

27. Saleemuddin A, Govender P, Farraye FA. Nocardia pneumonia in a patient with Crohn's disease receiving 6-mercaptopurine and infliximab. J Crohns Colitis. 2014;8(7):708-709.

28. Al-Tawfiq JA, Al-Khatti AA. Disseminated systemic No- cardia farcinica infection complicating alefacept and infliximab therapy in a patient with severe psoriasis. Int J Infect Dis. 2010;14(2):e153-157.

29. Wendling D, Murad M, Mathieu S, Berger E, Rumbach L. Systemic nocardiosis in a case of rheumatoid arthritis treated with tumor necrosis factor blockers. J Rheumatol. 2008;35(3):539-542.

30. Doraiswamy VA. Nocardia infection with adalimumab in rheumatoid arthritis. J Rheumatol. 2008;35(3):542-543.

31. Sidney G, Smith RSB. Disseminated Nocardia infection associated with infliximab (Abstract). USA: American College of Gastroenterology 69th Annual Scientific Meeting Orlando, 2004.

32. Singh JA, Wells GA, Christensen R, Tanjong Ghogomu E, Maxwell L, Macdonald JK, Filippini G, et al. Adverse effects of biologics: a network meta-analysis and Cochrane overview. Cochrane Database Syst Rev. 2011;2:CD008794.

33. Morel J, Constantin A, Baron G, Dernis E, Flipo RM, Rist S, Combe B, et al. Risk factors of serious infections in patients with rheumatoid arthritis treated with tocilizumab in the French Registry REGATE. Rheumatology (Oxford). 2017;56(10):1746-1754. 